\title{
MONITORING CHANGES IN URBAN LANDSCAPE PATTERN, USING ALOS AVNIR-2 AND WORLDVIEW-2 IMAGERIES
}

\author{
GÜZELMANSUR GÜRKAN, A.* - SAKALLI, S. \\ Mustafa Kemal University, Faculty of Architecture, Department of Landscape Architecture \\ 31040 Antakya, Hatay, Turkey \\ (phone: +90-326-221-4112; fax: +90-326-221-1489) \\ *Corresponding author \\ e-mail: aysgmansur@hotmail.com \\ (Received $4^{\text {th }}$ Apr 2017; accepted $3^{\text {rd }}$ Jul 2017)
}

\begin{abstract}
Recent studies show that urbanization is most affected form of land transformation that intensely influences biological diversity and human life. Quantifying urban landscape pattern is essential for monitoring and assessment of urbanization. The aim of this contribution is monitoring short term changes in urban landscape pattern of Hatay province located in Mediterranean region of Turkey. Hatay is a key region in the ongoing conflict in Syria because of the border and will remain so during the postconflict transition period. As a result of this situation the urban area has recently undergone extensive land transformations. These land transformations were detected by satellite images of Alos Avnir-2 (2008) and WorldView-2 (2014) using geographic information system (GIS) and remote sensing (RS). Methodology comprised three stages; (1) collecting data and image pre-processing, (2) land cover mapping using object- based image analysis and accuracy assessment (3) landscape change analysis. Landscape change analyses were employed to quantify land cover changes from 2008 to 2014. As a results of the study, forest area decreased from $23,2 \%$ to $14,6 \%$. On the other hand urban area increased from $22,5 \%$ to $29,9 \%$. This paper demonstrated that urban and forest changed rapidly in this part of the Mediterranean region of Turkey.
\end{abstract}

Keywords: Hatay, landscape change analysis, quantify, object-based classification

\section{Introduction}

Monitoring land change science has recently emerged as a fundamental component of global environmental change and sustainability research (Gutman et al., 2004, Rindfuss et al., 2004; Turner et al., 2007; Liu and Yang, 2015; Janisova, 2014). Rapid urbanization and urban sprawl have significant impact on conditions of urban ecosystems. Accurate and updated information on the status and trends of urban ecosystems is needed to develop strategies for sustainable development and to improve the livelihood of cities. The ability to monitor urban land-cover/land-use changes is highly desirable by local communities and by policy decision makers alike. With increased availability and improved quality of multi-spatial and multi-temporal remote sensing data as well as new analytical techniques, it is now possible to monitor urban land cover/ land-use changes and urban sprawl in a timely and cost-effective way (Yang et al., 2011; Güzelmansur and K1lıç, 2013). Since urbanization interferes with many ecological systems and processes, geospatial information on its implications is essential for land use planning and management.

Different classification methodologies and data types have been used for land use/land cover (LU/LC) change detection and database updating. In particular, objectbased image analysis (OBIA) techniques enable connecting information from the image with database information (Berberoglu and Curran, 2004; Ming et al., 2015). In OBIA approaches, the pixels are not individually classified but combined into homogenous 
groups (objects) and classified together (Walter, 2004; Mui et al., 2015). Unlike spectral methods employed in pixel based classifications, OBIA are based on segmenting the image into homogeneous pixels (Image objects) and classifying these objects using spectral, spatial, textural, relational and contextual methods. Rather than treating the image as a collection of pixels to be classified on their individual spectral properties, the image pixels can be initially grouped into segments and the object segments can then be classified according to spectral and other criteria, such as shape, size and relationship to neighboring objects. In this way, objects with heterogeneous reflectance values, such as tree canopy, can still be recognized despite their heterogeneity (Zhou and Troy, 2008; Bhaskaran et al., 2010). In comparison with pixel approaches, additional spatial and contextual information can be obtained from objects in OBIA (Blaschke, 2010, Ruiz et al., 2011, Hussain et al., 2013; Wu et al., 2015), which can be easily stored and linked to a database as attributes or features (Gill-Yepes et al., 2016).

Object-based image analysis is quickly gaining acceptance among remote sensors, and has demonstrated great potential for classification and change detection, compared to pixel-based approach (Blanschke, 2010; Myint et al., 2011; Zhou and Troy, 2008; Yu et al., 2016). The advantage of the object-based approach is that it offers new possibilities for image analysis because image objects can be characterised by features of different origin incorporating spectral values, texture, shape, context relationships and thematic or continuous information supplied by ancillary data. Integration of additional knowledge is a valuable means to distinguish ecologically meaningful habitat types that don't have necessarily very distinct spectral features. Moreover integration with existing vector-databases can be achieved during all steps of the classification proces (Bock et al., 2005; Gürkan, 2016)

RS provides a cost-effective alternative to the ground-based survey for land use/landcover mapping and change analysis. (Jensen, 2004; Liu and Yang, 2015; Cserhalmi and Erdös, 2016).

The study employed in hatay province. It is located in the Mediterranean region of Turkey and it is in the border of Syria. So, Hatay is a key region in the ongoing conflict in Syria and will remain so during the post-conflict transition period. Massive population displacements and widespread destruction are linked to the highly strategic nature of the city due to the ethnic and sectarian diversity of the population (Asaad and Shamaly, 2016). Approximatly 500.000 Syrian refugees has been settled to Hatay after conflict acording to local goverments. Some of the refugees settled in the urban area. Therefore, the urban area has recently undergone extensive land transformations. Building development is the most important drive that led to these changes. Hence, the aim of this contribution is to monitor short term changes in urban landscape pattern of Hatay province for 6-year time period between 2008 and 2014. For this purpose, Alos Avnir-2 (2008) and WorldView-2 (2014) images were used.

Urban changes were detected by rectified satellite images of Alos Avnir-2 and Worldwiev-2. The study which performed with the help of RS and GIS mainly consists of three objectives: (1) to land cover mapping using object- based image analysis (2) to make accuracy assesment (3) to quantify land use changes. 


\section{Materials and Methods}

\section{Study area}

Hatay is a city in the Mediterranean region of the southern part of Turkey, with a population of 500.749 (TÜIK, 2016) (Fig. 1). The study area is a $8^{*} 9 \mathrm{~km}$ area including the Hatay city center. It is surrounded by forests of Amanos Mountain in the west, Amik Plain in the north and Habibi Neccar Mountain in the east. Orontes River is the main river crossing the urban area. Climate regime is Mediterranean climate characterized by a mild winter during which about $67 \%$ of the annual precipitation of $1124 \mathrm{~mm}$ falls, and a hot dry summer. Average annual temperature reaches a maximum of $44^{\circ}$ in the summer and a minimum of $-15 \mathrm{C}^{\circ}$ in the winter, with an average annual temperature of $18{ }^{\circ} \mathrm{C}$. Parent material consists mostly of conglomera, calcaire and alluvial. Mediterranean vegetation consists of evergreen forest of Pinus brutia, and shrublands composed of maquis, and garrigues (Guzelmansur and Kılıç, 2013).

\section{Data sets}

Alos (Avnir-2): The image collected on 2008 from Advanced Visible and Near Infrared Radiometer type 2 (Avnir-2) of the Alos Avnir-2 were used in this study. The image data has $100 \mathrm{~cm}$ spatial resolution and comprise four visible wavebands corresponding to blue $(0,42$ to $0,50 \mu \mathrm{m})$, green $(0,52$ to $0,60 \mu \mathrm{m})$, red $(0,61$ to 0,69 $\mu \mathrm{m})$ and near infra-red $(0,76$ to $0,89 \mu \mathrm{m})$.

WorldView-2: The image collected on September 2014 from WorldView-2 Ortoready Pansharpened (WV2-NT/ORPNP). The image data has $50 \mathrm{~cm}$ spatial resolution and comprise tree wavebands and 16 bites.

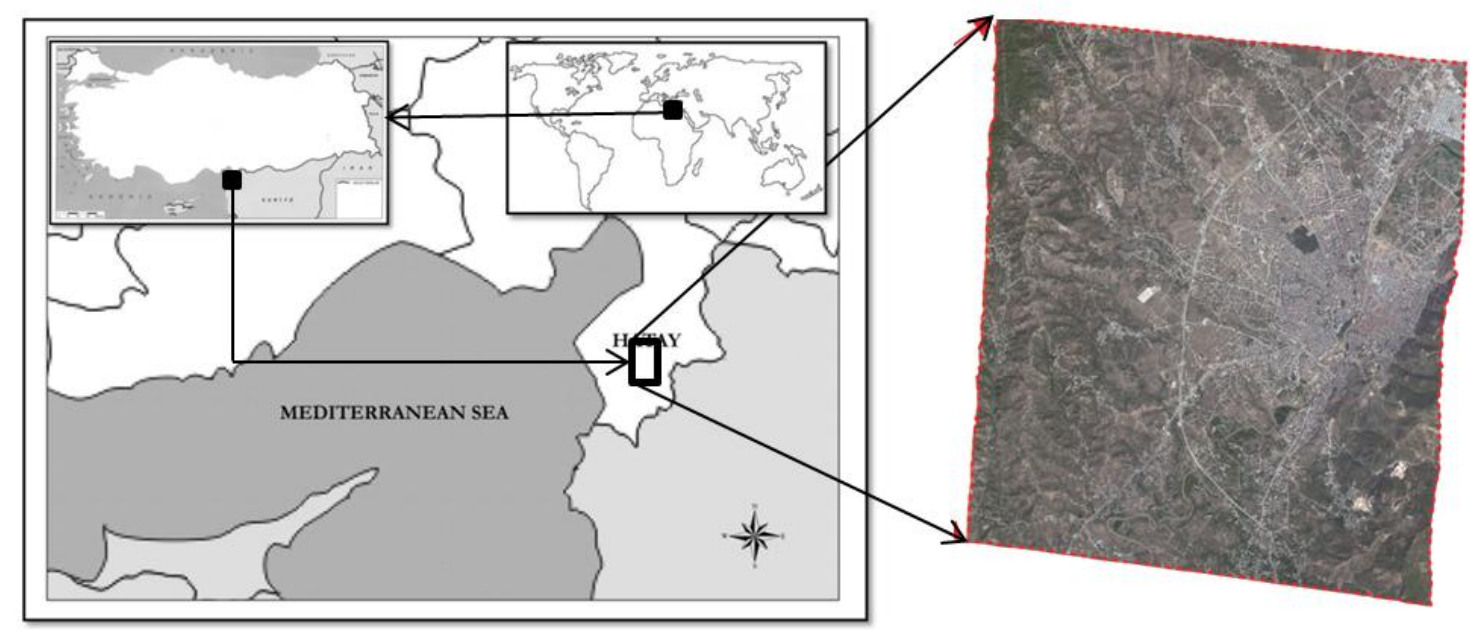

Figure 1. Site location of study area

\section{Methodology}

The study comprises 3 stages: (1) collecting data and image pre-processing, (2) land cover mapping using object based image analysis and accuracy assesment (3) landscape change analysis. 


\section{Image preprocessing}

The image was geometrically corrected and geocoded to the Universal Transverse Mercator (UTM), WGS-84 zone 37 coordinate system using 1/25.000 scale topographic maps. A minimum of 20 regularly distributed ground control points (GCPs) were selected from the image. Resembling was performed using a nearest neighbor algorithm. The transformation had a root mean square (RMS) error of less than $<0.5$ pixels indicating that the image was accurate within one pixel. A nearest neighbor algorithm takes the value of the pixel in the input image that is closest to computed coordinate.

\section{Object-based image classifications}

Object-based methodology was adopted for image classification performed for each images captured between 2008 and 2014. Object based image analysis provides rich opportunities for expert (predefined) knowledge integration for the classification process, it also makes the classification more vulnerable to operator-/scene-/ sensor/target-dependency, which in turn hampers the repeatability and transferability of rules (Witharana and Lynch, 2016). It was preferred in the classification process. Image objects are described and classified by using a wide range of attributes including image features such as spectral variables, shape, texture, size, but also potentially thematic data such as slope, aspect, soil properties provided by digital maps. Image objects may also be classified by reference to expert rules such as rules based on the spatial relationship between objects (contiguity) or the distance between objects (Mathieu et al., 2007). The software used in this research was ArcGIS 10.2. Object-based classification have been recently used in a wide range of application fields (Bock, 2003), landscape pattern analysis (Ivits et al., 2005), fire monitoring (Gitas et al., 2004), land cover/land use mapping in rural (Van der Sande et al., 2003) or urban environments (Meinel et al., 2001) and topographic feature extraction (Repaka et al., 2004; Mathieu et al., 2007; Gürkan, 2016). Seven main categories of land cover types were identified: urban area, agriculture, forest, shrubland, bare soil, water, industry. Additionally, field surveys were carried out to verify these land cover types.

\section{Accuracy assessment}

An error matrix, and a Kappa coefficient for each classification were generated. Once a classification exercise has been carried out, there is a need to determine the degree of error in the end-product. These errors could be thought of as being due to incorrect labelling of the pixels. Conversely, the degree of accuracy could be sought. First of all, if a method allowing a 'reject' class has been used then the number of pixels assigned to this class (which is conventionally labelled as "0") will be an indication of the overall representativeness of the training classes. If large numbers of pixels are labelled as " 0 " then the representativeness o the training data sets is called into question - do they adequately sample the feature space? The most manly used method of representing the degree of accuracy of a classification is to build confusion matrix (error matrix) (Mather, 1999).

Kappa Statistic is an index that compares the agreement against what might be expected by chance (Eq. 1): 


$$
k=\frac{N \sum_{i=1}^{r} x_{i i}-\sum_{i=1}^{r}\left(x_{i+} * x_{+i}\right)}{N^{2}-\sum_{i=1}^{r}\left(x_{i+} * x_{+i}\right)}
$$

Kappa coefficient $(\mathrm{k})$ is used to summarise the information provided by the error matrix. The $\mathrm{x}_{\mathrm{ii}}$ are the diagonal entries of the confusion matrix. The notation $\mathrm{x}_{\mathrm{i}+}$ and $\mathrm{x}_{+\mathrm{i}}$ indicates, respectively, are the sum of row I and the sum of column I of the confusion matrix. $\mathrm{N}$ is the number of elements in the confusion matrix. Rows total $\left(\mathrm{x}_{\mathrm{i}+}\right)$ for the confusion matrix shown in Table 1 are listed in the column headed (I) and columns totals are given in the last row (Mather, 1999).

\section{Landscape change analysis}

Early approaches to measure urban expansion with RS focused on simple band ratios, image thresholding, and image differencing to discern broad-scale changes at the urban-rural fringe (Howarth and Boasson, 1983; Jensen and Toll, 1982; Martin and Howarth, 1989; Shalaby and Tateishi, 2007), while more recent developments accommodate the high spectral variability of urban areas by exploiting spatial or polarimetric dimensions in satellite datasets (Bhaskaran, et al., 2010; Ghimire, et al., 2010; Shaban and Dikshit, 2001; Taubenböck et al., 2012; Shalaby and Tateishi, 2007).

Landscape change analysis was based on image classification. The 2008 and 2014 images classified using object-oriented methodology. Classified images were overlaid to extract landscape change information. Quantitative areal data of the overall land cover changes as well as gains and losses in each category between 2008 and 2014 can be compiled. In order to analyze the rate, and location of land cover changes, a set of 'gains' and 'losses' images for each category was also produced. These 'change' images were overlaid with an image of the city, which was constructed in a vector GIS and it converted into a raster format with the resolution of 10 meters. This GIS overlay intended to find landscape change information within the city.

\section{Results}

\section{Land cover mapping}

Images of 2008 and 2014 were preprocessed and classified to create land cover maps. The two land-cover maps discriminated seven classes: urban, agriculture, forest, shrub land, bare, water and industry (Fig. 2). The urban class included settlement area, cemetery, educational institutions, parks and their roads. Agricultural lands were split in two classes to increase their discrete with other land-cover classes; annual agriculture and horticulture. The forest class included natural forest areas (Pinus brutia Ten.) and maquies vegetation. Shrubland is easily sacrificed for different land uses to Sarcopoterium spinosum (L.) Spach. The most important water flow of the City is Asi (Orontes) River classified as water. Industry consists from commercial (small industrial site) and the other minor saleable area in the city and it's around. 

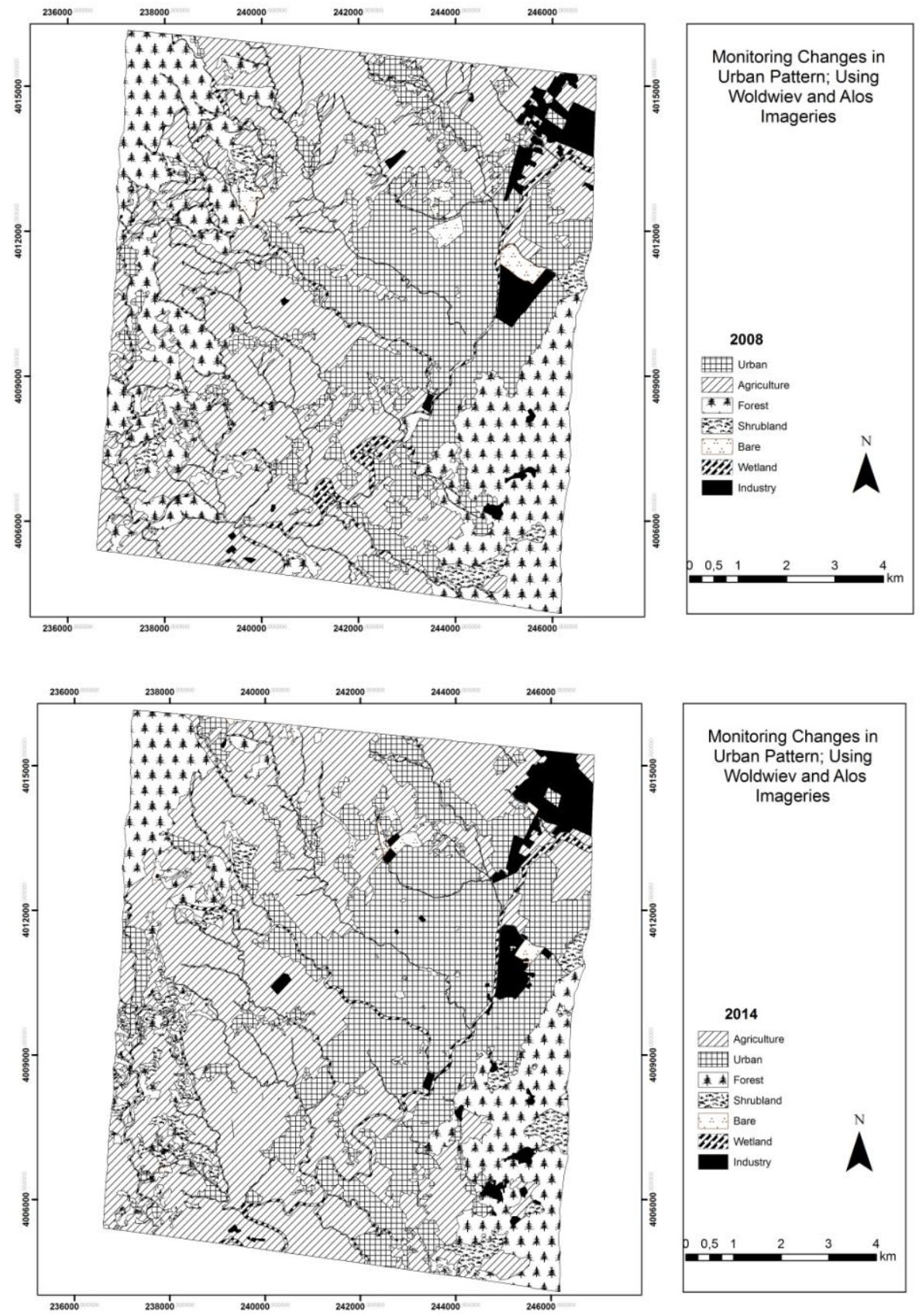

Figure 2. Land cover in 2008 and 2014

\section{Validating classification results}

Table 1 and Table 2 shows that indicate the level of consistency between observed land cover for 2008 and 2014. Confusion or error matrix consist for seven classes. The row labels are those given by an operator using ground reference data. The column labels are those generated by the classification procedure. The four right-hand columns are as follows: (I) number of pixels in class from ground reference data; (II) estimated classification accuracy (percent); (III) class i pixels in reference data but not given label by classifier; and (IV) pixels given label I by classifier but not class I in reference data (Mather, 1999). The sum of the diagonal elements of the confusion matrix is for year of 
2008 is 160 , and the overall accuracy is therefore $(160 / 179) \times 100=90,67 \%$ (Table 1). The sum of the diagonal elements of the confusion matrix for year of 2014 is 185 , and the overall accuracy is therefore $(185 / 204) \times 100=90,68 \%$ (Table 2).

Overall acuuracies and Kappa values were over \%86 in most cases which is acceptable rate for accuracy (Foody, 2010). Water had the highest accuracy values. Forest, urban, bare, industry, agriculture follow respectively. Accuracies for urban areas in 2008 classification are slightly lower than 2014 but still around $90 \%$. Resolution of the image of 2008 lower than 2014, that is why the accuracy is higher than 2008. High classification accuracies showed that, use of enhanced images provided opportunities for mapping this variability effectively. The fact that an object-based image analysis was adopted also helped to produce very accurate classifications.

Table 1. The sum of the diagonal elements of confusion matrix for 2008

\begin{tabular}{l|r|r|r|r|r|r|r|r|r|r|r}
\hline LU/LC Type & Urban & $\begin{array}{l}\text { Agri- } \\
\text { culture }\end{array}$ & Forest & $\begin{array}{l}\text { Schru- } \\
\text { bland }\end{array}$ & Bare & Water & Industry & I & II & III & IV \\
\hline Urban & 30 & 2 & 1 & 1 & 1 & 0 & 1 & 36 & 88,31 & 6 & 3 \\
Agriculture & 1 & 25 & 1 & 1 & 1 & 0 & 0 & 29 & 86,20 & 4 & 5 \\
Forest & 0 & 1 & 40 & 0 & 0 & 0 & 0 & 41 & 97,56 & 1 & 3 \\
Schrubland & 0 & 2 & 1 & 25 & 1 & 0 & 0 & 29 & 86,20 & 4 & 4 \\
Bare & 0 & 0 & 0 & 2 & 15 & 0 & 0 & 17 & 88,24 & 2 & 3 \\
Water & 0 & 0 & 0 & 0 & 0 & 10 & 0 & 10 & 100,00 & 0 & 0 \\
Industry & 2 & 0 & 0 & 0 & 0 & 0 & 15 & 17 & 88,23 & 2 & 1 \\
Total & 33 & 30 & 43 & 29 & 18 & 10 & 16 & 179 & & 19 & 19 \\
\hline
\end{tabular}

Table 2. The sum of the diagonal elements of confusion matrix for 2014

\begin{tabular}{l|r|r|r|r|r|r|r|r|r|r|r}
\hline LU/LC Type & Urban & $\begin{array}{l}\text { Agri- } \\
\text { culture }\end{array}$ & Forest & $\begin{array}{l}\text { Schru- } \\
\text { bland }\end{array}$ & Bare & Water & Industry & I & II & III & IV \\
\hline Urban & 35 & 3 & 1 & 1 & 1 & 0 & 1 & 43 & 83,33 & 7 & 4 \\
Agriculture & 1 & 30 & 1 & 1 & 1 & 0 & 0 & 34 & 88,24 & 4 & 6 \\
Forest & 1 & 1 & 40 & 0 & 0 & 0 & 0 & 42 & 95,24 & 2 & 3 \\
Schrubland & 0 & 2 & 1 & 30 & 1 & 0 & 0 & 34 & 88,24 & 4 & 5 \\
Bare & 0 & 0 & 0 & 3 & 20 & 0 & 1 & 24 & 83,33 & 4 & 3 \\
Water & 0 & 0 & 0 & 0 & 0 & 15 & 0 & 10 & 100,00 & 0 & 0 \\
Industry & 2 & 0 & 0 & 0 & 0 & 0 & 15 & 17 & 88,24 & 2 & 2 \\
Total & 39 & 36 & 43 & 35 & 23 & 15 & 17 & 204 & & 29 & 23 \\
\hline
\end{tabular}

\section{Quantifying from to changes}

In this study, landscape change analyses technique was applied. It is the most obvious method of change detection, which requires the comparison of independently produced classified images.

Fig. 2 show the result maps of land cover in 2008 and 2014. These resulting maps were investigated and compared. Urbanization increased from $22,5 \%$ to $29 \%$ which it means approximately 7.000 hectar (Table 3). Additionally, agricultural areas icreased from $44,4 \%$ to $45,6 \%$. Shrubland and industry also increased from year of 2008 to 2014. On the other hand, forest area decreased from $23,2 \%$ to $14,6 \%$. The most prominent change in the study area was replacement of forest by urbanization, agriculture and shrubland. Replacement from forests to urban areas was observed. These changes occured especially around the villages of Ballı̈z, Doğanköy, Günyazı and Toygarlı. These areas have been used for recreational activities in the recent years. Additionally, 
the figure show that expansion of agriculture over shrubland, resulted in a decrease in this cover type. Rapid urbanization is evident in the study area.

Table 3. LU/LC of 2008 and 2014

\begin{tabular}{l|r|c|r|r}
\hline LU/LC Type & $\mathbf{2 0 0 8}(\mathbf{h a})$ & $\mathbf{2 0 0 8}(\boldsymbol{\%})$ & $\mathbf{2 0 1 4}(\mathbf{h a})$ & $\mathbf{2 0 1 4}(\boldsymbol{\%})$ \\
\hline Urban & 23.773 & $\mathbf{2 2 , 5}$ & 30.635 & $\mathbf{2 9 , 0}$ \\
Agriculture & 46.941 & 44,4 & 48.174 & 45,6 \\
Forest & 24.550 & $\mathbf{2 3 , 2}$ & 15.423 & $\mathbf{1 4 , 6}$ \\
Schrubland & 1.771 & 1,7 & 3.113 & 2,9 \\
Bare & 1.047 & 1,0 & 989 & 0,9 \\
Water & 4.689 & 4,4 & 3.442 & 3,3 \\
Industry & 2.852 & 2,7 & 3.846 & 3,6 \\
Total & 105.623 & 100,0 & 105.623 & 100 \\
\hline
\end{tabular}

Analysis results showed that area coverage of various LU/LC types is unbalanced. Agriculture and urban are the most extensive LU/LC types in the study period. Agriculture covered 46941 hectar of land, which made up $44 \%$ of the study area in 2008. This reached to 48174 hectar in 2014 , corresponding to $46 \%$ of total area. Urban cover that occupied 23773 and 30635 hectar of land in 2008 and 2014, respectively, has the second largest extent. Forest areas covered 24550 hectar, in 2008. However, this area decreased because of urban, agriculture and shrubland. It declined from 24550 ha in 2008 to 15423 in 2014. Maquies are trimmed to plantation of olive trees. These cause to replacement from forest to agriculture. Additionally, some recreational activities like picnic, ect. couse the urbanisation of forest area.

Fig. 3 provide information about the LU/LC conversions, which showed that most of the changes took place in urban, agricultural and forest areas. Maquie vegetation and pine forest make up the forest in the study area. As previously mentioned, agriculturerelated changes comprised conversions from/to agriculture. Urbanization mostly took place at the expense of agriculture, forest, bare areas, shrubland and industry. The fact that higher rates of urbanization takes place on agriculture areas is an important finding worthy of consideration and it requires attention in development planning for the region. Forest area decreased in the study period of the years from 2008 to 2014.

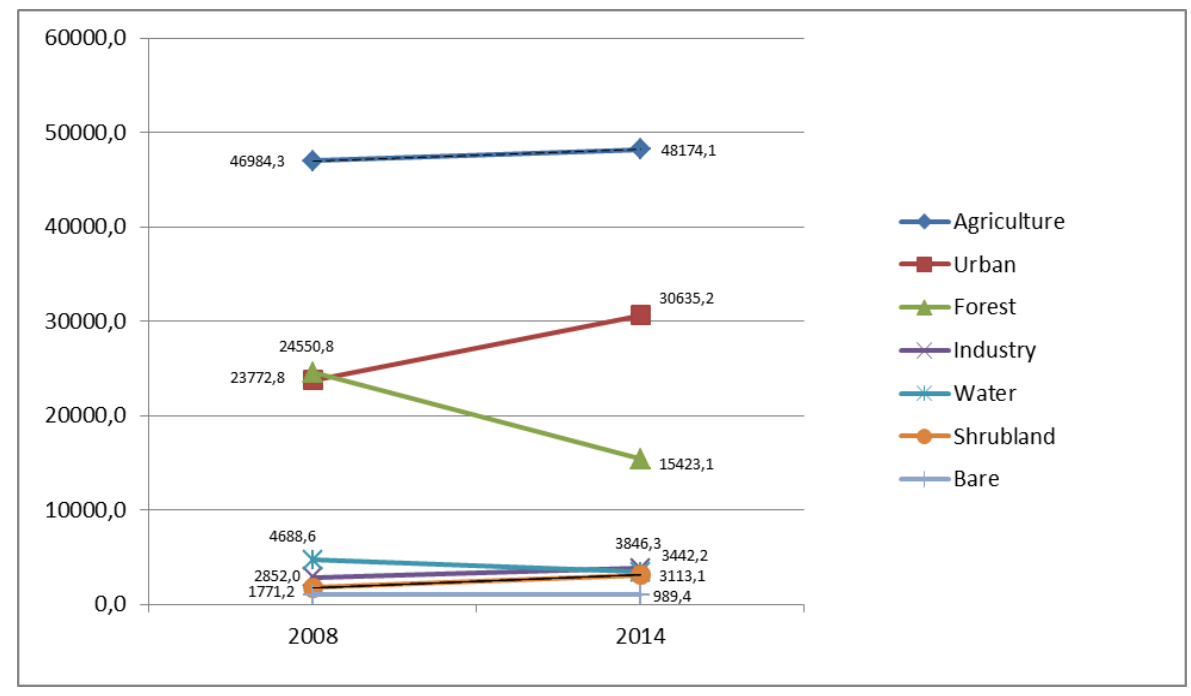

Figure 3. LU/LC changes from 2008 to 2014 
Forest areas have been turned into cultivated, urban or shrub areas. Although the same classification method is used in some areas in both images, it is found that forest areas have been transformed into areas used for other purposes as a result of the difference in image resolution of two images. Worldview-2 image resolution was $50 \mathrm{~cm}$ while the other was $100 \mathrm{~cm}$. Some shrubland areas around the forest patches classified as forest areas because of resolution of image. This is one reason for the decrasing the forest area from 2008 to 2014. However, urban area has been extensive and some natural areas convert to some cultural land uses such as urbanization and agriculture.

\section{Discussion}

Alphan and Çelik (2016), used landscape pattern while Esbah et al. (2010) used landscape stucture metrics. Esbah et al, employed change analyses that highlighted the increase in artificial surfaces and decrease in arable lands and forests in a protected area. Alphan and Çelik (2016), used landscape pattern to monitore changes in coastal zone. They highlited dramatic transformations from agriculture to build-up areas. Similar results were obtained in our study; urban area increased rapidly between 2008 and 2014. However, forest area decreased dramatically between this time period. From environmental planning and management point of view, degredation of forest areas is an important disquiet.

\section{Conclusions}

The contribution assessed urban landscape changes using landscape change analysis. The analysis included classifications of two different sensors of Alos Avnir-2 and Worldview-2 which have high spatial resolution. As a consequence of landscape change analysis, there is an increase in urban development and forest related changes occured. This makes it essential to properly analyze changes for establishing appropriate local development strategies and monitoring of development in the urban area. When facing such severe and rapid land-cover changes, one requirement for decision-making is to be able project future changes under certain assumptions. Such projections also contribute to increase awareness of the ecological consequences of growing pressures. However, this study focused on a period of time which is probably too short to understand the land-cover change process in all its complexity. Yet, this period is important because of the ongoing conflict in Syria which led to the settlement of Syrian refegees in Hatay's urban area. Attempts must now be made to increase the period of observation of the past (i.e. before the resettlement) by analyzing longer temporal series of land cover data.

Current remote sensing techniques enable the application of monitoring in temperate regions of the world (Berberoglu et al., 2000; Berberoğlu and Akın, 2009). The contribution presents the results of OBIA classification-based mapping of an area around the city of Hatay in Turkey, using images from two different high resolution sensors of Alos Avnir-2 and Worldview -2. Land cover changes were quantified in terms of percentage of area affected and rates or change.

The results presented in the paper show that OBIA is a valuable method for monitoring changes in urban landscape pattern which are useful for urban planners and may be interpreted to raise awareness for the use of natural resources. OBIA is performing very well when applied to Worldview-2 and Alos Avnir-2 imagery. The 
method provides flexibility in the ability to transfer classification schemes developed recent images where a fair set of ground truth data is available.

High resolution satellite images like WorldView-2 and Alos Avnir-2 images can be used for these kinds of studies. It can save time and effort for fieldwork. But some disadvantage in the study was, if the both images have same spatial resolution the classification results will be more accurate. Additionally there are also some disadvantages such as high price of digital imagery, difficulty in finding qualified staff to work about GIS.

\section{REFERENCES}

[1] Alphan, H., Çelik, N. (2016): Monitoring changes in landscape pattern: use of Ikonos and Quickbird images. - Environmental monitoring and assessment 188(2): 81.

[2] Berberoglu, S., Akin, A. (2009): Assessing different remote sensing techniques to detect land use/cover changes in the eastern Mediterranean. - International Journal of Applied Earth Observation and Geoinformation 11(1): 46-53.

[3] Berberoglu, S., Curran, P. J. (2004): Merging spectral and textural information for classifying remotely sensed images. - In: Remote sensing image analysis: including the spatial domain. Springer Netherlands, 113-136.

[4] Berberoglu, S., Lloyd, C. D., Atkinson, P. M., Curran, P. J. (2000): The integration of spectral and textural information using neural networks for land cover mapping in the Mediterranean. - Computers \& Geosciences 26(4): 385-396.

[5] Bhaskaran, S., Paramananda, S., Ramnarayan, M. (2010): Per-pixel and object-oriented classification methods for mapping urban features using Ikonos satellite data. - Applied Geography 30(4): 650-665.

[6] Blaschke, T. (2010): Object based image analysis for remote sensing. - ISPRS Journal of Photogrammetry and Remote Sensing 65 (2010): 2-16.

[7] Bock, M., Xofis, P., Mitchley, J., Rossner, G., Wissen, M. (2005): Object-oriented methods for habitat mapping at multiple scales-Case studies from Northern Germany and Wye Downs, UK. - Journal for Nature Conservation 13(2): 75-89.

[8] Cserhalmi, D., Erdős, L. (2016): Accuracy assessment of retrospective vegetation maps considering succession patterns. - Applied Ecology And Environmental Research 14(1): $37-45$.

[9] Esbah, H., Deniz, B., Kara, B., Kesgin, B. (2010): Analyzing landscape changes in the Bafa Lake Nature Park of Turkey using remote sensing and landscape structure metrics. Environmental Monitoring and Assessment 165(1): 617-632.

[10] Foody, G. M. (2010): Assessing the accuracy of land cover change with imperfect ground reference data. - Remote Sensing of Environment 114(10): 2271-2285.

[11] Ghimire, B., Rogan, J., Miller, J. (2010): Contextual land-cover classification: incorporating spatial dependence in land-cover classification models using random forests and the Getis statistic. - Remote Sensing Letters 1(1): 45-54.

[12] Gil-Yepes, J. L., Ruiz, L. A., Recio, J. A., Balaguer-Beser, Á., Hermosilla, T. (2016): Description and validation of a new set of object-based temporal geostatistical features for land-use/land-cover change detection. - ISPRS Journal of Photogrammetry and Remote Sensing 121: 77-91.

[13] Gitas, I. Z., Mitri, G. H., Ventura, G. (2004): Object-based image classification for burned area mapping of Creus Cape, Spain, using NOAA-AVHRR imagery. - Remote Sensing of Environment 92(3): 409-413.

[14] Gutman, G., Janetos, A.C., Justice, C.O., Moran, E.F., Mustard, J.F., Rindfuss, R.R., et al.(2004): Land change science: Observing, monitoring and understanding trajectories of change on the earth's surface. - Springer, Dordrecht; New York. 
[15] Guzelmansur, A., Kilic, S. (2013): Land-Cover Classification Using Advanced Land Observation Satellite Imagery: A Case Study of The Peri-Urban Region of Antakya. Journal Of Food Agriculture \& Environment 11(2): 1178-1181.

[16] Gürkan, A. (2016): Biotope mapping in an urban environment for sustainable urban development-a case study in southern part of turkey.- Applied ecology and environmental research 14(4): 493-504.

[17] Haj Asaad, A., Shamaly, O. (2016): The Effects of the Conflict in the Orontes River Basin in Syria, in Water Resources Management in the Lower Asi-Orontes River Basin: Issues and Opportunities, Geneva: Graduate Institute of International and Development Studies; Istanbul.- MEF University, 11-17.

[18] Howarth, P. J., Boasson, E. (1983): Landsat digital enhancements for change detection in urban environments. - Remote sensing of environment 13(2): 149-160.

[19] Hussain, M., Chen, D., Cheng, A., Wei, H., Stanley, D. (2013): Change detection from remotely sensed images: From pixel-based to object-based approaches. - ISPRS Journal of Photogrammetry and Remote Sensing 80: 91-106.

[20] Ivits, E., Koch, B., Blaschke, T., Jochum, M., Adler, P. (2005): Landscape structure assessment with image grey-values and object-based classification at three spatial resolutions. - International Journal of Remote Sensing 26(14): 2975-2993.

[21] Janišová, M. (2014): The role of surrounding landscape in determining species richness of mesic grasslands in pannonian basin and carpathian mountains. - Applied Ecology and Environmental Research 12(1): 251-266.

[22] Jensen, J. R., Toll, D. L. (1982): Detecting residential land-use development at the urban fringe. - USA, Photogrammetric Engineering and Remote Sensing 48 (Apr.): 198

[23] Jensen, J.R. (2004): Introductory digital image processing. - Prentice Hall, Upper Saddle River.

[24] Liu, T., Yang, X. (2015): Monitoring land changes in an urban area using satellite imagery, GIS and landscape metrics. - Applied Geography 56: 42-54.

[25] Martin, L. R., Howarth, P. J. (1989): Change-detection accuracy assessment using SPOT multispectral imagery of the rural-urban fringe. - Remote Sensing of Environment 30(1): 55-66.

[26] Mather, P. M. (1999): Land cover classification revisited. - In: Atkinson, P. M., Tate, N. J. (eds) Advances in remote sensing and GIS analysis. Chichester, John Wiley and Sons, 7-16.

[27] Mathieu, R., Freeman, C., Aryal, J. (2007): Mapping private gardens in urban areas using object-oriented techniques and very high-resolution satellite imagery. - Landscape and Urban Planning 81(3): 179-192.

[28] Meinel, G., Neubert, M., Reder, J. (2001): The potential use of very high resolution satellite data for urban areas-First experiences with IKONOS data, their classification and application in urban planning and environmental monitoring. - Regensburger Geographische Schriften 35: 196-205.

[29] Ming, D., Li, J., Wang, J., Zhang, M. (2015): Scale parameter selection by spatial statistics for GeOBIA: Using mean-shift based multi-scale segmentation as an example. ISPRS Journal of Photogrammetry and Remote Sensing 106: 28-41.

[30] Mui, A., He, Y., Weng, Q. (2015): An object-based approach to delineate wetlands across landscapes of varied disturbance with high spatial resolution satellite imagery. - ISPRS Journal of Photogrammetry and Remote Sensing 109: 30-46.

[31] Myint, S. W., Gober, P., Brazel, A., Grossman-Clarke, S. Weng, Q. (2011): Per-pixel vs. object-based classification of urban land cover extraction using high spatial resolution imagery. - Remote sensing of environment 115(5): 1145-1161.

[32] Repaka, S. R., Truax, D. D., Kolstad, E., O’Hara, C. G. (2004): Comparing spectral and object based approaches for classification and transportation feature extraction from high resolution multispectral imagery. - ASPRS Annual Conference Proceedings 23-28. 
[33] Rindfuss, R.R., Walsh, S.J., Turner, B.L., Fox, J., (2004): Mishra Developing a science of land change: challenges and methodological issues. - Proceedings of the National Academy of Sciences of the United States of America 101 (39): 13976-13981

[34] Ruiz, L. A., Recio, J. A., Fernández-Sarría, A., Hermosilla, T. (2011): A feature extraction software tool for agricultural object-based image analysis. - Computers and Electronics in Agriculture 76(2): 284-296.

[35] Shaban, M. A., Dikshit, O. (2001): Improvement of classification in urban areas by the use of textural features: the case study of Lucknow city, Uttar Pradesh. - International Journal of Remote Sensing 22(4): 565-593.

[36] Shalaby, A., Tateishi, R. (2007): Remote sensing and GIS for mapping and monitoring land cover and land-use changes in the Northwestern coastal zone of Egypt. - Applied Geography 27(1): 28-41.

[37] Shalaby, A., Tateishi, R. (2007): Remote sensing and GIS for mapping and monitoring land cover and land-use changes in the Northwestern coastal zone of Egypt. - Applied Geography 27(1): 28-41.

[38] Taubenböck, H., Esch, T., Felbier, A., Wiesner, M., Roth, A., Dech, S. (2012): Monitoring urbanization in mega cities from space.- Remote sensing of Environment 117: 162-176.

[39] Turner, B.L., Lambin, E.F., Reenberg A., (2007): The emergence of land change science for global environmental change and sustainability. - Proceedings of the National Academy of Sciences of the United States of America 104 (52): 20666-20671.

[40] TÜIK (2016). Turkish Statistical Institute, official website. https://biruni.tuik.gov.tr/medas/?kn=95\&locale=tr, date of access: January 2016.

[41] Van der Sande, C. J., De Jong, S. M., De Roo, A. P. J. (2003): A segmentation and classification approach of IKONOS-2 imagery for land cover mapping to assist flood risk and flood damage assessment. - International Journal of applied earth observation and geoinformation 4(3): 217-229.

[42] Walter, V. (2004): Object-based classification of remote sensing data for change detection. - ISPRS Journal of photogrammetry and remote sensing 58(3): 225-238.

[43] Witharana, C., Lynch, H. J. (2016): An Object-Based Image Analysis Approach for Detecting Penguin Guano in very High Spatial Resolution Satellite Images. - Remote Sensing 8(5): 375.

[44] Wu, X., Peng, J., Shan, J., Cui, W. (2015): Evaluation of semivariogram features for object-based image classification. - Geo-spatial Information Science 18(4): 159-170.

[45] Yang, C., Everitt, J. H., Murden, D. (2011): Evaluating high resolution SPOT 5 satellite imagery for crop identification. - Computers and Electronics in Agriculture 75(2): 347354.

[46] Yu, W., Zhou, W., Qian, Y., Yan, J. (2016): A new approach for land cover classification and change analysis: Integrating backdating and an object-based method. - Remote Sensing of Environment 177: 37-47.

[47] Zhou, W.Q., Troy, A. (2008): An object-oriented approach for analysing and characterizing urban landscape at the parcel level. - International Journal of Remote Sensing 29: 3119-3135. 